\title{
Task Switching in Online Multitasking Behaviors
}

\author{
Naipeng Chao, Cheng Wang, and Yi Li
}

\begin{abstract}
Information era of fragmentation, multitasking behavior has been occupying our lives in many aspects, especially on Internet. This research focuses on the unsynchronized online multitasking, which called task switching, to explore switching paths and individual differences in multitasking behaviors. We distinguish between switching frequency and task completion quality in task switching behaviors. The online tasks are classified to cognitive task, emotional task and social task in this study. A total of 145 college students participated in experiments and psychological questionnaires. This research found: an emotional task tends to switch to a cognitive task, a cognitive task tends to switch to an emotional task, and the possibility of a social task switching to the other two types tends to equality. In the different experimental groups, namely extraversion, neuroticism, anxiety, cognitive style, work memory span are all significant correlated with the task switch times, and extraversion, neuroticism, anxiety are significant correlated with task completion quality. We also found the existences of the transit task and the following task in task switching behavior.
\end{abstract}

Index Terms-Multimedia, multitasking, online behavior, task switching.

\section{INTRODUCTION}

Multitasking behavior has been an essential human behavior in daily life. For example, a mother takes care of several children or students note in lectures. As an 'old phenomenon', multitasking behavior becomes more and more important due to the development of digital communication technologies, especially on Internet.

Multitasking behavior requires performing either simultaneously or in rapid alternation. [1] It often presents in three ways: (1) individual does two or more tasks simultaneously; (2) individual changes rapidly among tasks; (3) individual completes a series of tasks in order.

Cognitive scientists have studies multitasking for decades. Task switching is an important aspect. Rubinstein et al. (2001) found that multitasking between different types of tasks can reduce productivity. [2] Frequent switching makes users lose their sense of control, even have intent chaos when browsing, unable to determine which information they really need.

In previous studies, scholars have been trying to build multitasking coordination framework for information behavior [3] to reduce the cost of multitasking. Differently, this research aims to reveal the path of task switching, to explore the influence of psychological characteristics contributing to online multitasking behaviors.

Multitasking behavior can be offline, online or online to

Manuscript received May 22, 2015; revised January 12, 2016.

The authors are with the Communication and Journalism Department, Nanjing University, No.22, Rd. Hankou, Nanjing, 210093, China (e-mail: npchao@nju.edu.cn,849141952@qq.com, eu41@live.cn). offline. This research focuses on online multitasking behaviors. Platforms of multitasking behaviors are defined as PC connected to Internet.

\section{RESEARCH QUESTIONS}

People often switch among different types of tasks such as talking on the telephone, computing, reading, and information seeking [2].

The classification of tasks in online multitasking behavior is not generally acknowledged. Zhang divides tasks into specific tasks and related tasks. A specific task from is relatively independent, while a related task needs to seek information between objects, compare nodes associated to solve problems. [4] Spink \& Park (2006) studied multitasking information behavior in public libraries. They classify tasks as Internet searching, library browsing, reading, personal communication and others. [5] They also found that task-switching follows a certain path.

In this research, tasks are reclassified according to demands. Wang \& Tchernev prose four media use needs: emotional, cognitive, social and customary habitual. [6] According to them, in this research, task types are divided into cognitive task, like attaining information; emotional task, for leisure and social tasks, as interpersonal communication.

Complex task switching involves three phases: desire to task switch, task switch and switching back to a previous task. The research focuses on successive or rapid alternation multiple-task performance rather than simultaneous multiple-task performance [7].

According to Spink's study, individual follows certain path when multitasking. In previous studies, task types are not divided. As tasks are divided into three types, is there a certain path of task-switching between types?

RQ 1: In online multitasking behaviors, do individuals follow certain paths of task-switching?

Individual difference exists in offline multitasking behaviors. Grady et al. have verified the relationship between ages and multitasking behaviors. [8], [9] Ophir studies the relationship between genders and multitasking behaviors [10].

Webster attributes impacts of multitasking into media factors and user factors, which including demographic characteristics and psychological characteristics. [11] Cognitive sciences task multitasking as a waste of time. Studies found that multitasking leads to increased level of stress and health-related problems. [2] On contract, communication studies show that there are probably positive aspects in multitasking among certain people. Thus, this research emphasize psychological difference.

In studies of cognitive style, which is an essential variable in online behavior, field dependence or field independence 
is an important dimension. Ford's study found that individuals who have stronger field independence complete information searching tasks better and more active. [12] On the contrary, individuals with field dependence spend more time and steps to complete searching.

Logan (2004) describes the role of working memory in executive control during task switching. [2] The concept of working memory was first proposed by Baddeley and Hitch. Working memory is a platform for storage and handling of information when people perform, to process, combine and transform memories. [13] Working memory span is an essential factor to working memory, as Colom et al. found working memory span can predict the performance of multitasking [14].

Wang and Tchernev found a correlation between neuroticism and media multitasking behavior. It shows that high neurotic individuals intend to media multitasking behaviors. But there is no significant relationship between extraversion and multitasking behavior [6].

Self-efficacy refers to a feeling of self-assurance. Zhang Xiaolan found that high-score junior high school students have higher self-efficacy. [15] Similarly, users with higher self-efficacy are easier to recover tasks form interruption on Internet.

Anxiety is a subjective sense of tension. Previous studies focus on relationship between academic achievements rather than task switching itself. Poolton found that anxiety level influences operative learning performance [16].

Thus, the research measures participants' cognitive style, working memory span, psychological characteristics associated with Internet behaviors, like extraversion, neuroticism, self-efficacy, anxiety, in order to explore:

RQ 2: How do these psychological characteristics affect individual online multitasking behavior?

\section{METHOD}

\section{A. Participants}

A total of 145 valid participants, aging from 18 to 29 years old, are recruited from Nanjing University, of which $61.4 \%$ are females. $78.9 \%$ of the participants are from the departments of humanities

\section{B. Design}

The research is composed by 4 parts: a questionnaire about the extroversion, neuroticism, self-efficacy and anxiety of participants, a test of cognitive style, a test of working memory span and main tasks.

As the main test, this research has a between-group design: participants are divided into 9 groups: 4 for emotional tasks, 2 for cognitive tasks, 2 for social tasks and 1 control group, which aims to explore the frequencies and paths of participants' task-switching behaviors.

\section{Materials}

\section{1) Psychology questionnaire}

Extroversion and neuroticism are adapted from EPQ. The extroversion scale is consist of 21 questions (alpha=0.830). The neuroticism scale is consisted of 24 questions (alpha=0.773).

The self-efficacy scale is based on Wang (2001), [17] alpha $=0.882$. The anxiety scale is adapted from Charles D. Spielberger (1970) [18], alpha $=0.852$.

\section{2) Test of cognitive style}

Using GEFT investigates field dependent-independent cognitive style.

\section{3) Working memory span}

Based on the research of Schmader \& Jonhs (2003) [19], the test is composed with 36 pairs. Each pair has an equation and a term written in Chinese. For example, at start, ' $(2 \times 3)$ $+2=8$ ?' appears on screen. Participants press ' $\mathrm{J}$ ' for true or ' $\mathrm{F}$ ' for false to judge the equation. After $3 \mathrm{~s}$, the term '解决 (solve)' replace the equation. The team stays 2 s. Participants are required to read it aloud. There is $1 \mathrm{~s}$ pause between pairs. 3-5 pairs compose a round. After each round, participants are told to write down the terms they have remembered. There are 9 rounds in total.

The score is counted as every correct term stands for 1 point.

\section{4) Main tasks}

Emotional groups are required to watch 3 clips of different emotion level videos. Each lasts about 6 minutes. The emotional level is judged by 7 students, whose descriptions are transferred into numerical values based on the scale of Feng (2004) [20].

Cognitive groups are divided into complex and simple cognitive tasks groups. All of them should search 15 different articles about the Huangyan Island standoff between China and Philippines on Internet. The complex group are supposed to conclude attitude changes of bilateral governments in more than 100 words.

Participants in social groups are incognizant about each other. They have two different tasks. Half of participants have a discussion on the topic 'Is it better to take an occupation or advanced study after graduation?' The others cognize each other in 1 hour. All the discussions take place in QQ groups.

Control group surf freely on Internet.

\section{Procedure}

Participants take questionnaire, working memory span test and main tasks successively. The main task last for an hour. Participants could finish the tasks whenever they want during an hour. They are not allowed to leave labs even if the tasks are completed.

\section{RESUlTS}

\section{A. The Performance Multitasking Behavior}

To describe the online task switching, we use 'task switching frequency' and 'task completion quality'.

Emotional task completion quality, mainly to test participants' emotional changes during watching video material. Participants were given a Chinese Sentiment Adjectives Scale to fill before, after watching videos to calculate the scores changes when watching videos. This research shows that mood changes are most obvious in groups of strong negative emotions, and groups of strongly positive emotions change least.

Cognitive task completion quality is judged by at least six 
students scoring in the range of 1-10 points, the mean is the final point. In this study, the group of simple cognitive task $(m=7.6)$ is slightly higher than the group of complex cognitive task $(m=7.0)$.

Social task completion quality accords to the level of participation that participants are during the discussion, including statements frequency, speak correlation, opinions representation, etc. Besides, more than six students are invited to grade. In this study, the group of low difficulty $(m=4.8)$ is lower than the high social difficulty $(m=6.3)$.

Task switching times are collected by software. In this study, the maximum times of the task switching is 36 , the minimum is 0 , an average of 6.17 . For frequency distribution, switching task or 4 times, 2 times, 1 times, 6 times, accounting for respectively $16.6 \%, 14.5 \%, 11.7 \%$, $9.0 \%$, are the largest numbers of switches appear.

To verify the path of task switching, this research task a paired samples $t$-test to explorer whether there is a task switching preference.

\section{1) Cognitive task switching}

According to Table I and Table II, cognitive/emotional and cognitive/social switching times are $1.53(\mathrm{SD}=1.505)$ and $0.83(\mathrm{SD}=1.898)$.

TABLE I: TASK SWITCHING FREQUENCY BETWEEN COGNITIVE AND OTHER

\begin{tabular}{llll}
\multicolumn{4}{c}{ TYPES } \\
\hline \hline Mean & Std Deviation & Std. err. \\
\hline Cognitive-emotional & 1.53 & 1.505 & .131 \\
Cognitive-social & .83 & 1.897 & .164 \\
\hline
\end{tabular}

TABLE II: PAIRED SAMPLE TEST OF COGNITIVE-EMOTIONAL TASK SWITCHING AND COGNITIVE-SOCIAL TASK SWITCHING

\begin{tabular}{|c|c|c|c|c|c|}
\hline \multirow{3}{*}{$\begin{array}{l}\text { Cog./emo.-cog./so. task } \\
\text { switching frequency }\end{array}$} & $\begin{array}{l}\text { Paired } \\
\alpha=0.05\end{array}$ & difference & \multirow{2}{*}{$t$} & \multirow{2}{*}{$d f$} & \multirow{2}{*}{ Sig. } \\
\hline & M & Std Deviation & & & \\
\hline & .707 & 2.593 & 3.143 & 132 & .002 \\
\hline
\end{tabular}

For paired-sample test, the average difference was 0.707 , $\mathrm{SD}=2.593$, the switching frequency difference between the two groups the confidence of $95 \%$ confidence interval $(0.262,1.152)$, paired $t$-statistic values of $3.143(d f=132)$. Two-tailed test is significant $(p=0.002)$. Therefore, cognitive tasks are more inclined to switch to emotional task.

\section{2) Emotional task switching}

According to Table III and Table IV, cognitive/emotional and cognitive/social switching times are $1.48(\mathrm{SD}=1.611)$ and $0.77(\mathrm{SD}=1.712)$.

TABLE III: TASK SWITCHING FREQUENCY BETWEEN EMOTIONAL AND

\begin{tabular}{llll}
\multicolumn{4}{c}{ OTHER TYPES } \\
\hline \hline & Mean & Std Deviation & Sd. err. \\
\hline Emotional-cognitive & 1.48 & 1.611 & .142 \\
Emotional-social & .77 & 1.712 & .151 \\
\hline
\end{tabular}

TABLE IV: PAIRED SAMPLE TEST OF EMOTIONAL-COGNITIVE TASK SWITCHING AND EMOTIONAL-SOCIAL TASK SWITCHING

\begin{tabular}{|c|c|c|c|c|c|}
\hline \multirow{3}{*}{$\begin{array}{l}\text { Emo./cog-em } \\
\text { o./so. task } \\
\text { switching } \\
\text { frequency }\end{array}$} & \multicolumn{2}{|c|}{$\begin{array}{l}\text { Paired difference } \\
\alpha=0.05\end{array}$} & \multirow[b]{2}{*}{$t$} & \multirow[b]{2}{*}{$d f$} & \multirow[b]{2}{*}{ Sig. } \\
\hline & M & $\begin{array}{l}\text { Std } \\
\text { Deviation }\end{array}$ & & & \\
\hline & .713 & 2.392 & 3.386 & 128 & .001 \\
\hline
\end{tabular}

For paired-sample test, the average difference was 0.713 , $\mathrm{SD}=2.392$, the switching frequency difference between the two groups the confidence of $95 \%$ confidence interval $(0.296,1.130)$, paired $t$-statistic values of $3.386(d f=128)$. Two-tailed test is significant $(p=0.001)$. So emotional task are more inclined to switch to cognitive task.

\section{3) Social task switching}

According to Table V and Table VI, social/cognitive and social/emotional switching times are $0.99(\mathrm{SD}=2.169)$ and $0.87(\mathrm{SD}=1.995)$.

TABLE V: TASK SWITCHING FREQUENCY BETWEEN SOCIAL AND OTHER

\begin{tabular}{llll}
\multicolumn{4}{c}{ TYPES } \\
\hline \hline & Mean & Std Deviation & Std. err. \\
\hline Social-cognitive & .99 & 2.169 & .187 \\
Social-emotional & .87 & 1.995 & .172 \\
\hline
\end{tabular}

TABLE VI: PAIRED SAMPLE TEST OF SOCIAL-COGNITIVE TASK SWITCHING AND SOCIAL-EMOTIONAL TASK SWITCHING

\begin{tabular}{|c|c|c|c|c|c|}
\hline \multirow{3}{*}{$\begin{array}{l}\text { Emo./cog-em } \\
\text { o./so. task } \\
\text { switching } \\
\text { frequency }\end{array}$} & \multicolumn{2}{|c|}{$\begin{array}{l}\text { Paired difference } \\
\alpha=0.05\end{array}$} & \multirow[b]{2}{*}{$t$} & \multirow[b]{2}{*}{$d f$} & \multirow[b]{2}{*}{ Sig. } \\
\hline & $M$ & $\begin{array}{l}\text { Std } \\
\text { Deviation }\end{array}$ & & & \\
\hline & .119 & 2.443 & .556 & 133 & .573 \\
\hline
\end{tabular}

For paired samples $t$-test results in table view, two-tailed test is not significant $(p=0.573)$. Therefore, social/cognitive and social/emotional task switching have no significant difference.

\section{B. Psychological Characteristics Associated with Online Multitasking Behavior}

The research measures the psychological characteristics of participants, including cognitive style, working memory, extraversion, neuroticism, self-efficacy and anxiety.

TABLE VII: CORRELATION BETWEEN PSYCHOLOGICAL CHARACTERISTICS AND TASK SWITCHING

\begin{tabular}{llll}
\hline \hline & & $\begin{array}{l}\text { Task switching } \\
\text { frequency }\end{array}$ & $\begin{array}{l}\text { Task } \\
\text { completion } \\
\text { quality }\end{array}$ \\
\hline $\begin{array}{l}\text { Strong positive } \\
\text { emotion }\end{array}$ & Cognitive style & $.509^{*}$ & \\
\hline $\begin{array}{l}\text { Weak positive } \\
\text { emotion }\end{array}$ & Extraversion & $-.488^{*}$ & \\
\hline $\begin{array}{l}\text { Weak negative } \\
\text { emotion }\end{array}$ & Anxiety & & $-.481^{* *}$ \\
\hline Simple cognition & Extraversion & $.536^{*}$ & \\
\hline $\begin{array}{l}\text { Complex } \\
\text { cognition }\end{array}$ & Neuroticism & & $-.509^{*}$ \\
\cline { 2 - 4 } $\begin{array}{l}\text { Low difficulty } \\
\text { social task }\end{array}$ & $\begin{array}{l}\text { Working memory } \\
\text { span }\end{array}$ & $.486^{* *}$ & $-.590^{*}$ \\
\hline$* p<0.05 ; * p<0.01$ & & & \\
& & & \\
\end{tabular}

Table VII shows: in strong positive emotional group, the cognitive style and task switching frequency showed a significant positive correlation; In weak positive emotional group, extraversion and task switching frequency showed a significant negative correlation; In weak negative emotional group, anxiety and task completion quality showed a significant negative correlation; In simple cognitive task group, extraversion and task switching frequency showed a significant positive correlation; In complex cognitive task group, neuroticism anxiety were associated with task completion quality showed a significant negative correlation; in low difficulty social task group, working memory span 
and task switching frequency showed a significant positive correlation.

\section{DISUSSION}

\section{A. Task Switching between Types}

Further analysis of task switching between emotional and cognitive and social tasks found that:

\section{1) Searching task is both the initial of emotional task,} but also a 'following task'.

Spink found that information seekers take information searching as a transit task. [21] Corollary to this study, this conclusion is also true but there is a slightly different that cognitive tasks act as a transit task between emotional tasks. For example, searching for videos between watching. Consequently, searching as a type of cognitive task becomes the starting task of emotional tasks.

In addition, a large number of participants in emotional task group search for the information about the videos they just watch. In this case, the searching task became a 'following task' of emotional task.

\section{2) Social task as a transit task, following task}

From the experimental data, the social task in this study plays more as a transit task or following task, such as browsing news, watch videos, etc. Different from cognitive task, social task does not appear to be a starting task or main tasks. As a result, social tasks appear the most in the three categories of tasks, while the chance of task switching to other two types of task appears equal.

\section{B. Psychological Characteristics and Online Multitasking Behavior}

The correlation between self-efficacy and multi-task behavior between does not established. Although $\mathrm{Hu}$ Longjiao's study found that higher self-efficacy users can better control certain negative emotions and are easier to recover from an interrupt task to the main task. [22] In Hu's design, the interruption is an important variable, distinguishing from active and passive task switching. In this study, participants are asked to finish main tasks without restrictions, which may cause the difference with Hu's study.

In strong positive emotional group, cognitive style and task switching times are positively correlated, that is, the stronger the field independence is, the more participants switch tasks. In Hu's study, individual with strong field dependence spend more time to complete the search, and needs more steps. However the result is opposite in emotional task groups. Hu's study is focused on cognitive task, but in this study there is no significant correlation between two factors in cognitive task group.

In the low difficulty social task group, working memory span and task switching times there was a significant positive correlation. In multitasking behavior study, working memory as an important concept in cognitive psychology, often used to analyze the behavior of multitasking. Participants with strong working memory span can carry more diverse information. In low difficulty social task group, since the discussion takes place in QQ group, message are more complicated and messy, it allows participants more opportunities for task switching. As a result, the one with stronger working memory span is able to accommodate a larger amount of information. He may be more inclined to participate in several QQ chats, which leads to the increase of task switching.

Previous studies found that when working memory information is not properly allocated, will cause a decline in the quality of task execution. Since the limited capacity of working memory is an important feature, the working memory span might have a negative correlation between the completion qualities, but this study shows no evidence.

An inconsistent situation occurs in two groups. In weak positive emotional group, extraversion negatively correlates with task switching frequency, while in the simple cognitive task group, extraversion positively correlates with the frequency of task switching. As the videos in weak positive emotional group brings more happiness, wiliness of participates is lower than cognitive groups, where participants need to perform a large number of search tasks, extraversion personality present as 'sensational seeking' during the information search process. Overall, the correlation between extraversion and task switching needs to be further verified.

In the complex cognitive task group, neuroticism and task completion quality showed a significant negative correlation; and in a weak negative emotions group and complex cognitive task group, anxiety is correlated with task completion quality. Research concerning the relationship between neuroticism and anxiety with multitasking behavior is rare, researchers are more concerned about academic performance and neuroticism or anxiety correlation between personalities. The task completion quality can be seen as an academic reaction, especially in the complex cognitive group.

\section{CONCLUSIONS}

This research focuses on two questions: (1) the path of task-switching in online multitasking behavior. (2) As to individual differences: whether psychological characteristics will affect the performance of multitasking behavior.

The research was the first to distinguish between tasks: cognitive, emotional and social tasks on online task-switching behaviors. Further experimental study found: among the three types of tasks, the one who is doing the emotional task more inclined to switch to social tasks. Cognitive task prefers to emotional task switching, and the possibility of social task switching to emotional and cognitive tasks has no significant difference. In the strong positive emotions group, cognitive style and task switching frequency showed a significant positive correlation; in the weak positive emotions group, extraversion and task switching frequency showed a significant negative correlation; in weak negative emotions group, anxiety and task completion quality showed a significant negative correlation; in the simple cognitive task group, extraversion and task switching frequency showed a significant positive correlation; in complex cognitive task group, nervousness, anxiety were presented with the task completion quality significant negative correlation; in the low difficulty social task group, working memory span task switching times and 
showed a significant positive correlation.

In this research, we also found that during the online multitasking behavior, there was a 'transit mission': Participants always perform transit tasks during the process of task switching. For example, a certain participant starts the task from browsing Weibo, after completing a series of tasks, like searching news, watch videos, the participant will return to Weibo, beginning to a new round of tasks. In this case Weibo performants as a transit task between different series of tasks. Another example. The main task in the social task groups, some participants use QQ chat as a transit task between different tasks and QQ chats. QQ chats could become the starting point for task switching, also the focus of task switching. Actually, the "transit task" in online process can be divided into several processes. Does the 'transit task' really exist during the online task switching? What are the regulars to select the 'transit task'? These are all worthy of further exploration.

Taking account of the feasibility of experimental studies, this research was carried out mainly between university students. This is obviously not valid enough to reflect the entire sample of Internet users' multitasking behavior. In future research, expanding the range of samples are needed to test the existing results better and to describe the online multitasking behaviors more accurately. In addition, how does online multitasking behaviors contribute to the different use of Internet is also a subject to be explored in the further research.

\section{REFERENCES}

[1] J. S. Rubinstein, D. E. Meyer, and J. E. Evans, "Executive control of cognitive processes in task switching," Journal of Experimental Psycholog, vol. 7, no. 4, pp. 763-797, 2001.

[2] A. Spink, C. Cole, and M. Waller, "Multitasking behavior," Annual Review of Information Science and Technology, pp. 93-118, 2007.

[3] A. Spink and C. Cole, New Directions in Human Information Behavior, Springer, 2006, pp. 137-154.

[4] Z. J. Zhang, Y. J. Ren, and F. Su, "Effects of structure task type and navigation on performance in searching hypertext information," Acta Psychologica Sinca, vol. 36, no. 5, pp. 534-539, 2004.

[5] A. Spink, F. Alvardo-Alberrio, B. Narayan, J. Brumfield, and M. Park, "Multitasking information behavior in public libraries: A survey study," Journal of Librarianship and Information Science, vol. 39, no. 3, pp. 177-186, 2007.

[6] Z. Wang and J. M. Tchernev, "The 'Myth' of media multitasking: Reciprocal dynamics of media multitasking, personal needs, and gratifications," Journal of Communication, vol. 62, pp. 493-513, 2012.

[7] R. D. Rogers and S. Monsell, "Costs of a predictable switch between simple cognitive tasksz," Journal of Experimental Psychology: General, vol. 124, pp. 207-231, 1995.

[8] C. L. Grady, M. V. Springer, D. Hongwanishkul, R. McIntosh, and G. Winocur, "Age-related changes in brain activity across the adult lifespan," Journal of Cognitive Neuroscience, vol. 18, no. 2, pp. 227-241, 2006.

[9] S. H. Jeong and M. Fishbein, "Predictors of multitasking with media: Media factors and audience factors," Media Psychology, vol. 10, pp. 364-384, 2007.
[10] E. Ophir, C. I. Nass, and A. D. Wagner, "Cognitive control in media multitaskers," PNAS, vol. 106, no. 37, pp. 15583-15587, 2009.

[11] J. Webster, P. Phalen, and L. Lichty, Rating Analysis, 2nd ed. Mahwah NJ: Lawrence Erlbaum Associates, 2000

[12] Ford, "Information-seeking and mediated searching," Journal of the American Society for Information Science and Technology, vol. 53, no. 9, pp. 728-735, 2002

[13] G. A. Bower, Recent Advances in Learning and Motivation, New York: Academic Press, 1974

[14] R. Colom, "Agustin martinez-molina. Intelligence, working memory, and multitasking performance," Intelligence, vol. 38, pp. 543-551, 2010.

[15] X. L. Zhang, "School-belong, self-efficacy and academic achievements in junior high school," M. A. thesis, Shaanxi Normal University, Xian, China, 2012.

[16] J. M. Poolton and R. Mark, "A comparison of evaluation, time pressure, and multitasking as stressors of psychomotor oprative performance," Surgery, vol. 149, no. 6, pp. 776-782, 2011.

[17] C. K. Wang, Z. F. Hu, and Y. Liu, "Evidence for reliability and validity of the Chinese version of general self-efficacy scale," Chinese Journal of Applied Psychology, vol. 7, no. 1, pp. 37-40, 2001

[18] C. Spielberger, R. Gorsuch, and R. Lushene, Manual for the State-Trait Anxiety Inventory, UB Institutional Repository, 1970.

[19] T. Schmader and M. Johns, "Converging evidence that stereotype threat reduces working capacity," Journal of Personality and Social Psychology, vol. 85, no. 3, pp. 440-452, 2003.

[20] S. H. Feng and X. T. Huang, "Fuzzy evaluation statistics for omtinal adjective semantics," Acta Psychologica Sinica, vol. 36, no. 6, pp 704-711, 2004.

[21] A. Spink, "Multitasking information behavior and information task switching," Journal of Documentation, vol. 60, no. 4, pp. 336-351, 2004.

[22] L. J. Hu, "Effects of interruption, feedback intervention and Internet self-efficacy on information search and emotion in WWW," M. A. dissertation, Zhejiang University, Hangzhou, China, 2010.

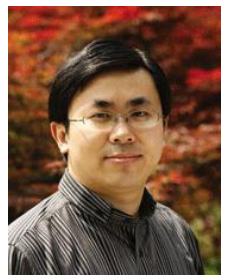

Naipeng Chao was born in Nanjing, China, on November 11, 1972. He received a doctor degree of information science and is a professor in Nanjing University, oriented in new media communication and interpersonal communication.

$\mathrm{He}$ has been the leader of several projects, including communication paradigms in politic news, index systems of online public opinions monitoring, influences of online computer games etc. He is now responsible for the Mobile Media Lab in the Department of Journalism and Communication in Nanjing University.

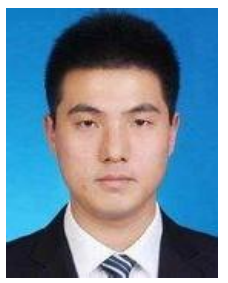

Cheng Wang was born in Shandong, China, on November 27, 1989. He is a journalist in Xinhua newspaper in Fujian.

His major was communication, oriented in online behavior during his master studies. This paper is a part of his final paper of master degree.

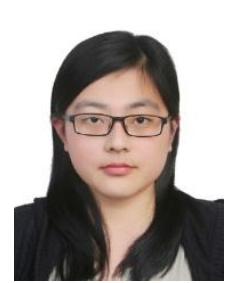

Yi Li was born in Nanjing, China, on October 2, 1990. He is a master student of communication in Nanjing University, oriented in online behavior.

She has engaged in several projects, including players behavior in MMORPG, task swithcing in online multasking behaviors etc. 